\title{
O ESVAZIAMENTO DO CAMPO ENTRE JOVENS CAMPONESES versus EDUCAÇÃO/ESCOLA
}

THE DRAIN FIELD BETWEEN RURAL YOUTH versus EDUCATION/SCHOOL

Odimar J. Peripolli ${ }^{1}$

\section{RESUMO}

Há em nosso país um esforço no sentido de implantar programas voltados aos jovens trabalhadores do campo. Iniciativas como o Projovem Campo, Nossa Primeira Terra, dentre outras, buscam fazer com que os jovens vêem o campo como possibilidade. A importâncias destas está em: vêm ao encontro de demandas históricas dos movimentos sociais e dos povos do campo; a juventude camponesa começa a ganhar visibilidade no cenário das políticas públicas voltadas ao campo. Vêm em boa hora, a considerar o descaso para com os jovens camponeses sobretudo, a falta de escola - processo histórico que tem e vem expulsando os jovens trabalhadores do campo de forma sistemática. Esta questão se torna cada vez mais séria na medida em que esse fenômeno tem como característica, o seu rejuvenescimento. Mais comumente naquelas regiões onde os jovens trabalhadores estão mais distantes dos grandes centros, em pequenas propriedades rurais, como é o caso dos assentamentos de reforma agrária (campo empírico de minhas/nossas pesquisas). O objetivo deste artigo é tencionar um pouco a realidade campo e a situação dos jovens camponeses nestes territórios, bem como o papel da escola neste cenário.

PALAVRAS-CHAVE: Educação/EJA - Jovem Camponês - Êxodo Rural.

\section{ABSTRACT}

There is a country in our effort to deploy programs geared to young field workers. Initiatives such as the Projovem Field, Our First Land, among others, seek to make young people see the field as possible. The sums of these are in: come to meet the 
demands of historical movements social and peoples of the field, the peasant youth beginning to gain visibility in the policy scenario public focused on the field. They come at a good time to consider the neglect of the rural youths - especially the lack of school - and the historical process that has been expelling the young workers in the field so systematically. This becomes increasingly serious in extent that this phenomenon is characterized by the rejuvenation. More commonly in those regions where young workers are more distant from major centers in small rural properties, as is the case of agrarian reform settlements (field Empirical my / our research). The aim of this article is to pull a little reality to the field and situation of young farmers in these areas, as well as the school's role in this scenario.

KEYWORDS: Education/EJA - Young peasant - Exodus countryside.

\section{INTRODUÇÃO}

A problemática educacional é inteligível quando pensada integrada e articulada com a estrutura e o processo de desenvolvimento do capitalismo entre nós (GRZYBOWSKI, 1986, p. 52).

Inicialmente, algumas considerações: a) há bastante tempo vem-se construindo alternativas no sentido de pensar a educação voltadas às populações que vivem e trabalham no campo; b) esta preocupação, sob diferentes formas, volta-se também aos jovens e adultos; c) muitos do que tentam retornar à sala de aula abandonam em definitivo os estudos; d) a escola sozinha não muda a realidade nem "fixa" os trabalhadores no campo; e) o fim das comunidades rurais tem uma relação estreita com a nucleação ou com o fechamento das escolas no/do campo.

O objetivo deste artigo é provocar algumas reflexões relacionadas ao movimento chamado "êxodo rural" entre os jovens camponeses que vivem e trabalham em pequenas propriedades rurais. Tomo como campo empírico as comunidades formadas por assentamentos de reforma agrária na região norte da Amazônia mato-grossense.

Orientam o trabalho, dentre outras questões: existe uma relação entre políticas públicas (agrícola e educacional) e a saída (ou não) dos trabalhadores do 
campo? Por que o êxodo, hoje, ocorre mais entre os jovens? Quais são as principais "cercas" que impedem que esta "erva daninha" seja, de fato, extirpada no campo, principalmente naqueles territórios formados pelos assentamentos de Reforma Agrária?

\section{O CAMPO PARA ALÉM DA VISÃO ROMÂNTICA...}

O cotidiano vivido por estes novos sujeitos (CARVALHO, 2005) que vivem e trabalham em assentamentos de reforma agrária do INCRA, como é o caso dos assentamentos no norte de Mato Grosso, mostra que o dia-dia, tanto nas lidas do campo quanto na escola, é muito mais complexo do que possa parecer. Nos assentamentos de reforma agrária (INCRA), a imagem é do puro abandono.

Em pleno século $X X I$ os povos do campo ainda não foram contemplados pelas muitas conquistas da modernidade. O contraditório está no fato de que a modernização da agricultura é um fenômeno de há muitas décadas. Mais: não é verdade que estes trabalhadores fazem parte de uma população considerada pouco relevante, residuais ou mesmo, avessa ao progresso. Pelo contrário, o protagonismo destes é uma das marcas deste início do século (SAUER, 2010)².

A modernidade elegeu a tecnologia como um dos seus pilares. Por que, então, esta não é colocada a serviço, ao dispor destes trabalhadores? Vale lembrar que, "se a terra e condições adequadas de produção permanecem como fundamentais, no rural contemporâneo proliferam também demandas por educação qualificada, [...]". Ou seja, para estes filhos de trabalhadores não basta a terra, as tecnologias apenas. É necessário, sobretudo, educação, escola, para que este lugar - mais do que um espaço onde se produz apenas mercadorias - seja um espaço que produza valores, princípios, para além daqueles impostos pelo projeto do capital para o campo, um espaço de vida, de vivência e convivência.

Não poderíamos avançar sem nos perguntar: que valores são estes tão propagados/propalados pelo capital, principalmente para o campo? Quem são os beneficiados pela modernização da agricultora? Não estaríamos confundindo e/ou colocando como fazendo parte de um só conceito/entendimento, crescimento econômico e desenvolvimento? Estas questões se justificam na medida em que, 
hoje, a escola parece estar centrada, única e exclusivamente, nos "conteúdos". Que conteúdos seriam estes e para que fins? Atender quem e para que finalidades? Por que estes precisariam dar conta de uma realidade que, nem sempre, diz respeito à escola?

Crzybowaky (1986, p. 48) nos chama a atenção para o tipo de pensamento que tem predominado nas últimas décadas sobre educação, qual seja: "uma concepção da educação enquanto fator de desenvolvimento, enquanto causa, enquanto investimento a ser dimensionado segundo taxas comparativas de rentabilidade e necessidades das estruturas ocupacionais". Para o autor, há a necessidade de superarmos e nos libertarmos "dos estreitos limites em que a educação é vista como caudatária do processo de desenvolvimento, [...], onde as questões educacionais se reduzem a uma contabilidade, em última análise, de custo/benefício" (Id, p. 49).

Precisamos pensar na possibilidade de um outro campo, com outros sujeitos: crianças, jovens e adultos vistos como protagonistas do processo desta construção, capazes de aprender mais do que os velhos conteúdos/disciplinas impostos por um projeto de escola burguesa-urbana, preocupada em tornar seu projeto de mundo/campo hegemônico; preparar trabalhadores "competentes", "úteis", obedientes, dóceis, etc., para atender os interesses do capital.

A escola no/do campo, nas mais diversas modalidades, ao que nos parece e, dado sua natureza, deve (rá)/pode (rá) superar esta visão reducionista de educação/escola: preparar mão-de-obra para um projeto de escola excludente e classista como é o projeto burguês de escola. O ponto de partida, acreditamos, está em fazermos da escola um lugar de significações, onde as iniciativas partam das experiências humanas, do que acontece no cotidiano dos sujeitos, do que, de fato, tenha sentido para a vida destes estudantes: aquelas coisas que, como diz Henz (2010, p. 11), "os toquem e os ajudem a viver melhor e ser mais felizes". Em outras palavras, uma escola significativa.

Há, no meio rural, um movimento de "recriação" (SAUER, 2010) deste espaço (meio rural para uns, para outros, campo). Junto à (re)conquista da terra, fruto de longas jornadas de lutas, vêm novas (e velhas) reivindicações. Ou seja, os que vivem e trabalham no e do campo, não aceitam mais o estigma da condição de inferiores: "jecas-tatus"; matutos a serem amansados, atrasados, a serem 
"civilizados"; da escola das primeiras letras apenas (ler, escrever e contar); da sala de aula sob qualquer estrutura física (barracões); dos professores sem a devida formação (leigos). Esta foi/é a escola que tem e vem expulsando tantos jovens do campo rumo aos centros urbanos.

Cabe estarmos atentos para o fato de que há um movimento no campo. Sementes vêm sendo plantadas, sempre ao modo/jeito de quem há bastante tempo lida com a terra. Os frutos começam a aparecer: querem, exigem o que lhes garante a legislação: educação de qualidade, acesso aos meios de comunicação, lazer, inclusão digital. Como diz Sauer (2010, p. 09), "acesso aos bens que, cada vez mais, tiram o rural de seu relativo isolamento e o aproxima da civitas" [cidadania].

Hoje, para os jovens e adultos que vivem e trabalham no campo, tomar uma decisão entre ficar e/ou sair do campo, é uma tarefa difícil de ser tomada. Há um conjunto de condicionantes imbricados nesse processo que, nas condições em que se encontram, nem sempre conseguem fazê-la da melhor forma possível. Ou seja, o simples desejo/querer "mudar de vida", "buscar uma vida melhor", não lhes é garantido na cidade. Mas, uma coisa é comum a todas as decisões e seguem uma dinâmica que aproxima a todos: migrar é/está sempre no limite das possibilidades. O êxodo, neste caso, quer significar - não o abandono, a desistência, o fim do sonho, mas, ao contrário -, acreditar no possível. Isso implica romper, dizer não ao estabelecido, partir para, buscar, começar tudo de novo.

Importa ressaltar, portanto, que as decisões (ficar - investir; sair "abandonar") tomadas tem uma relação direta com a construção e a efetivação (ou não) de políticas públicas (agrícolas e educacionais) que garantam a reprodução destes trabalhadores no campo. Daí a importância de que estas sejam construídas pelos verdadeiros interessados. Esta é a grande vantagem em pensarmos em termos de políticas públicas. Estas tem vantagens sobre os projetos, programas que, via regra, - além de terem um deternimado tempo de duração -, geralmente vêm prontos e a atender interesses de grupos e/ou pessoas. Ou seja, há que se caminhar no sentido de se construir políticas públicas voltadas a atender os interesses, as causas dos jovens do campo.

Por muito tempo, equivocadamente, pretendeu-se mudar a sociedade a partir da escola. Ou seja, a idéia de que a escola mudaria a realidade sozinha, o que valeria também, neste caso, para o campo. Ledo engano. Neste caso, faz-se 
necessário discutir primeiro o campo e a realidade que envolve estes sujeitos, depois a escola. Ou seja, ao falarmos de educação, temos que nos perguntar: em que campo estes sujeitos estão inserido? Em que condição vive? O que está sendo pensado e construído em termos de políticas públicas?

\begin{abstract}
Assim como é impossível pensarmos o trabalho independente da forma social determinada em que ele se exerce, do esmo modo não dá para pensar a educação em abstrato, sem considerar as condições que dão significado econômico e político à diversidade de formas de educação, de conteúdos e de pedagogias (GRZYBOWSKI, 1986, p. 51).
\end{abstract}

As pesquisas/estudos ${ }^{3}$ mostram um coletivo que, embora mais ou menos organizado, está dando uma nova fisionomia ao campo brasileiro. Isso vem ocorrendo também em Mato Grosso: camponeses vem dando uma nova "cara" ao campo. O protagonismo deste cenário tem a presença dos povos do campo (ribeirinhos, meeiros, arrendatários, pequenos agricultores, sem-terra, recém chegados...). O que comprova que os espaços da Amazônia norte mato-grossense se constitui pela sociediversidade e não, como tem sido mostrado durante tanto tempo, como sendo um território voltado à exploração capitalista e do agronegócio apenas (CARVALHO, 2005).

Neste novo quadro/cenário é que se percebe a necessidade de se construírem, no coletivo, novas concepções de campo, bem como novas concepções teóricas e práticas educacionais. Quando nossos olhares e práticas reclamam por um outro campo, ou seja, por um novo projeto de desenvolvimento par o campo, estes passam, necessariamente, pela garantia de que todos tenham acesso à educação. O campo mato-grossense ainda se caracteriza pelo analfabetismo, principalmente entre os adultos (PERIPOLLI, 2009).

Estas questões, assim colocadas, têm sua importância na medida em que mostram que a vida de cada um destes trabalhadores deva ser concebida e entendida como algo que se constitui dentro de uma dimensão social. Ou seja, viver no/do campo, o reproduzir-se enquanto trabalhador, no campo ou na cidade, tem uma relação direta com os diferentes aspectos e dimensões da vida social que os envolve. Estes, por sua vez, não podem ser entendidos sem que sejam inseridos no contexto em que surgem e se desenvolvem 
(LOMBARDI, 2005). Portanto, mais do que penarmos a escola, única e exclusivamente, temos que pensar o seu entorno.

Um olhar mais atento para o campo, principalmente para os assentamentos de Reforma Agrária do INCRA, como é o caso dos da região norte de Mato Grosso, nos coloca frente à materialização da imagem do abandono histórico pelos quais tem passado e ainda passam os camponeses no nosso país.

\section{0 "RURAL" VERSUS "CAMPO"}

O Brasil tem dado pouca (ou nenhuma) atenção para os jovens ao longo de sua história, principalmente para os jovens do campo. Tanto é que só a partir de 2005, com a criação da SEJ (Secretaria Especial de Juventude) e do CNJ (Conselho Nacional de Juventude), o tema (juventude) passou a ganhar "espaço formal no poder público federal" (CASTRO, 2006, p. 117). Nosso país "era um dos únicos países da América Latina a não ter esse espaço formal no poder público federal a tratar do tema" (Id.).

Dentre os muitos resultados negativos deste atraso, e que repercute até hoje, tem sido o abandono do campo por um grande número de trabalhadores. Hoje, mais especificamente, entre a população mais jovem e cada vez mais cedo (principalmente mulheres/moças), transformando o campo em território/espaço de homens e de velhos. É o fenômeno denominado "masculinização e envelhecimento do campo" (CAMARANO e ABRAMOVAY) ${ }^{4}$.

Como e/ou que jovem ficaria/fica no campo sem ter um mínimo de segurança de que terá condições de uma vida digna? Mais: a criação de uma SEJ não garante direitos aos jovens. Portanto, o esvaziamento do campo é decorrente da situação da pobreza, da miséria e, acima de tudo, da falta de perspectivas. Aqui entra o papel das lideranças/militância/intelectuais orgânicos, voltado no sentido de "instrumentalizar" estes sujeitos, via escola (EJA). Ou seja, possibilitar que estes façam uma outra leitura da realidade, qual seja: longe do "discurso da compreensão da História como determinação" (FREIRE, 2000), do discurso fatalista que apregoa o fim/morte do sonho e da utopia, tão comum e presente no discurso neoliberal. 
Assim colocado, o discurso cega/mata qualquer tipo de outras possibilidades que não aquelas impostas pelo projeto do capital para o campo. Logo, o fim do meio rural/campo, se coloca como algo inexorável.

A "expulsão" do homem do campo é a materialização desta forma de gestar o campo: pela lógica perversa do capital, onde tudo é visto sob a ótica do capital, onde tudo vira mercadoria e os interesses, única e exclusivamente, voltados para a idéia e prática do mercado/lucro.

A produção familiar camponesa, a cultura camponesa, não se enquadra nesta lógica. Pelo contrário, por isso vem sendo extinta e, o camponês, enquanto classe que vive do trabalho da terra, excluído/expropriado do processo/projeto ${ }^{5}$. É o que Fernandes (2002) chama de desintegração do campesinato.

Numa sociedade como a nossa, pelo uso e disponibilidade de tecnologia, não há como esconder as mazelas produzidas pelo capital no campo. O alto preço pago pelo meio ambiente denuncia um projeto de campo doente, materializado tanto no próprio campo quanto nos arredores das grandes, médias e até pequenas cidades (favelas, sem teto, sem emprego...).

Percebe-se, neste caso, um movimento campo - cidade - campo. Isso é mais comum, ao que nos parece, nos assentamentos de Reforma Agrária do INCRA, como é o caso da região norte de Mato Grosso ${ }^{6}$.

Estas muitas realidades mostram a complexidade das questões que envolvem o campo. Mais complexas do que simplesmente dizer que "[...] a maioria dos jovens que vivem nas áreas rurais não está interessada em retornar ao duro trabalho com a terra" (RIBEIRO, 2010, p. 197). E, numa referência aos jovens, questiona a autora (p. 198, grifo nosso) :

seria destino dos jovens e adultos trabalhadores ou imposição do capital, enquanto uma relação social, que haja um contingente cada vez maior de jovens e adultos trabalhadores, nas periferias urbanas, que não encontram emprego amparados pela legislação trabalhista?

Para a autora (p. 198), as mudanças não vão ocorrer a partir de iniciativas isoladas, "dissociadas de um projeto popular de sociedade". Esta forma de lidar com os problemas do campo, ressalta, não "atacam o problema na sua raiz" (p. 198). E conclui, ao afirmar que as transformações das condições sociais do 
campo estão relacionadas, não apenas à "conquista da terra sob novas relações de produção da vida, do conhecimento, da ciência e da arte", mas estas associadas a uma "formação humana radicada nessas relações" (198).

Portanto, discutir a questão do êxodo rural entre os jovens implica, necessariamente, pensar num conjunto maior de questões condicionantes. Não há como eleger um ou outro aspecto apenas, dado a complexidade das situações. Mas, uma coisa pode ser tomada como orientação: o primeiro caminho a ser buscado é a construção de políticas públicas voltadas aos interesses destes sujeitos. São estas que vão possibilitar confira condições dignas de vida, cidadania ${ }^{7}$.

Este entendimento é importante, pois, nossos jovens, hoje, já não se deixam levar/iludir tão facilmente como o foram "ontem" por velhos bordões que os colocavam na perspectiva de futuro ("jovem, futuro do país"). O jovem quer viver sua juventude hoje, e com dignidade. Essa nova postura, esse entendimento ("consciência") deve-se, em grande parte, ao trabalho das escolas e dos professores que, mesmo em condições precárias, fazem da EJA um espaço onde a escola é tomada como local de contradições.

Mas, quem é este jovem que vive no campo? O que teria ou tem de diferente de tantos outros jovens que vivem no meio urbano? Em que pesem as especificidades de um e de outro, das peculiaridades destes, nada. Simplesmente são jovens e, como tal, sonham com um presente e um futuro onde possam viver com dignidade; trabalhar; construir uma família - serem felizes. Portanto, creio que mais importante do que buscar definições para dizer o que é (ou não) ser jovem, é compreender que, nesta etapa da vida, pulsam sonhos, esperanças, utopias e que não cabem mais aquelas "velhas" e preconceituosas colocações/falas de que "os jovens não sabem o que querem".

Comumente, ao falarmos de juventude, as preocupações voltam-se ao meio urbano, não a do campo. Não por acaso, a considerar que o nosso país é urbano e, a grande maioria dos jovens, está nas cidades. Portanto, a presença destes é bem menor no campo do que nos centros urbanos, o que justificaria, de certa forma, a pouca atenção a este segmento. 
Embora estudos recentes ${ }^{8}$ fazem referência, tanto ao Brasil quanto a países mais desenvolvidos (França, USA), quanto a uma maior valorização dos chamados "espaços rurais", isso não significa que podemos comemorar o fim de um dos grandes problemas existentes no campo, o "êxodo rural", mais especificamente, no Brasil. Se para os países ricos, sair da cidade para o campo significa novas possibilidades de trabalho, de outras vivências, no nosso país, viver no campo, principalmente em pequenas propriedades rurais, assentamentos de Reforma Agrária, significa conviver com um mundo marcado pela falta de políticas públicas. Portanto, se há uma tendência à "valorização das regiões interioranas" (ABRAMOVAY, 2003, p. 11), o que em tese poderia significar uma reversão do atual quadro ("êxodo rural"), este fica comprometido, com certeza, pela saída dos jovens.

Diante do esvaziamento (sobretudo demográfico - o que não implicaria em negar o social, cultural, econômico - a ausência de jovens (sobretudo de jovens mulheres), o campo ganha, aos poucos, uma nova fisionomia: um lugar de velhos e de homens, "masculinização dos campos" (ABRAMOVAY, 2003; CASTRO, 2006, p. 118).

Qual a "culpa" da escola neste processo? Então, a escola tem culpa? Sim, só que, neste caso, a falta dela. Que modalidade de ensino é, comumente, oferecida aos filhos dos trabalhadores do campo? Via de regra, as primeiras séries ( $1^{\underline{a}}$ a $4^{a}$ ) e de $5^{\underline{a}}$ a $8^{\underline{a}}$ (mais escasso) séries do Ensino Fundamental. Muito raramente o Ensino Médio ${ }^{9}$. Aqui entram as intermináveis questões voltadas à nucleação e ao transporte escolar. Mas uma coisa é certa: se estes desejarem continuar seus estudos, terão que fazê-lo fora (cidade), longe da propriedade, da morada, da família. É o primeiro movimento, primeira "cerca" que se ergue contra estes jovens e que se coloca como definidora do futuro de muitos deles, sempre longe do campo.

Há que se levar em conta que, nestes casos, não só o jovem deixa o campo, mas toda a família. São estas situações (dentre outras) que, via de regra, fazem com que, muito cedo, os jovens se vêem obrigados a deixar/migrar o campo rumo à cidade.

Não há como tentar eleger "um" aspecto apenas como determinante quanto à possibilidade do jovem ficar e/ou sair do campo. Ou, como diz Castro 
(2006, p. 118), "[...] não se deve tratar a questão [refere-se àquelas enfrentadas pelos jovens] como paralela às enfrentadas pelos pequenos produtores familiares que hoje compõe o universo de produtores assentados". Em outros termos, os problemas vividos pelos jovens do campo são, antes de tudo, problemas comuns àqueles enfrentados pelos trabalhadores do campo, da classe que vive e trabalha na/da terra.

Estamos falando de questões decorrentes de um projeto de campo que se estabeleceu a partir de políticas do BM (Banco Mundial), décadas de 1960 e 1970, com a modernização do campo que, ao impor novas tecnologias para o campo, não beneficiou, da mesma forma que o agronegócio, a produção familiar camponesa. Expropriados pelo projeto modernizador, um sem-número de camponeses se viram obrigados a deixar o campo. Esse processo se reproduz hoje, também nos assentamentos de Reforma Agrária.

Estudos mostram que, em que pese os muitos problemas ainda existentes no campo, a escola ainda é um espaço de possibilidades, capaz de iniciar/mostrar aos filhos os passos em busca de uma "vida melhor". Mais: a escola é um espaço que aglutina, reúne, junta, a comunidade em terno de objetivos comuns. Tanto que, se sai a escola, morre a comunidade.

Esta valorização da escola deve-se ao fato de que, para muitas destas crianças, jovens e adultos, a "escolinha" ainda é um dos únicos lugares onde lhes é oportunizado aprender as "primeiras letras": ler, escrever, contar. Quiçá, em alguns e/ou em muitos casos, aprender a "ler a realidade" que os cerca; aprender a fazer a leitura do mundo (FREIRE, 2000).

Hoje, muito diferente do entendimento de que para trabalhar com a terra, mexer a enxada, lidar com o gado, não são necessárias as letras, a educação escolar - acesso, permanência (qualidade), - é vista como um direito, não mais uma dádiva e/ou um presente. Este é garantido pelo Constituição.

Qual o destino dos jovens que migram do campo? Os casos estudados (assentamentos do INCRA, norte de MT), apontam os centros urbanos, mais, comumente, cidades próximas aos assentamentos; ocupados em alguma atividade/trabalho que "exige pouco estudo", via de regra, mal remunerada; poucos 
dão continuidade aos estudos. As poucas exceções estão nas modalidades supletivo, à noite, como é o caso da EJA (Educação de Jovens e Adultos).

Ao que se percebe, para estes jovens, sem e/ou com pouco estudo, persiste a regra/lógica perversa do capital, qual seja: inserir-se muito cedo no mercado de trabalho junto a outros tantos jovens urbanos.

Se tomarmos como exemplo, o norte de Mato Grosso, as atividades aqui desenvolvidas, até pouco tempo, quando muitas das atividades "não exigiam estudo" (como era/é o caso do trabalho em/nas madeireiras), percebe-se que esse processo, em parte, ainda se reproduz, só que agora, também no campo: catar raízes, operar máquinas, lidar com o gado. A necessidade de trabalho/renda faz com que muitos jovens sejam obrigados a deixar os estudos muito cedo. Mas, o que mais pesa, ao que nos aprece, é a falta de perspectivas quanto à possibilidade em fazer um curso superior, mesmo na escola pública ${ }^{10}$.

Portanto, e ao que se percebe, as muitas questões são um pouco mais complexas do que parecem ser e/ou se mostram à primeira vista. Ou seja, há um sem-número de condicionantes ("cercas") que dificultam o entendimento do que ocorre na prática, no cotidiano destes sujeitos. Por isso, não basta que se garanta apenas o acesso à escola; nem mesmo projetos e programas que estejam de acordo com o que se propõe e/ou garantem a legislação. Na prática - lá bem distante de tudo e de todos (rincões), onde os professores recebem uma "autoridade" de vez em quando - as coisas são diferentes do que está escrito ou se propõe "de fora".

Minhas/nossas andanças, entre trilhas e estradas, mostram que as coisas que imperam o processo, o "bom" andamento das escolas rurais/do campo vão desde questões simples (material básico para manutenção e funcionamento da escola) até aquelas que têm um comprometimento maior quanto à qualidade da educação/ensino: falta de laboratório, biblioteca, transporte adequado, professor qualificado, metodologias e métodos que contemplam as especificidades do campo.

Portanto, quando as questões envolvem a educação, a escola rural/no/do campo e os jovens, estas devem ser pensadas de uma forma mais ampla. Ou seja, pensar o presente e futuro dos jovens do campo consistirá em construir um outro 
campo, uma outra escola; pensar um espaço onde haja terra para trabalhar, produção de renda, moradia, saúde, lazer, escola, vida digna.

Os jovens que vivem e trabalham no campo, hoje, não são iguais aos jovens "rurais" de ontem. Seus sonhos são outros, suas necessidades são outras. Quando afirma querer "buscar uma vida melhor", referirem-se a um conjunto de condições que possibilite serem cidadãos.

\section{CONCLUSÃO}

As discussões mostram que, embora haja uma revalorização dos espaços rurais/do campo, vista como um dos fenômenos demográficos importante neste início de século, o êxodo ainda é uma realidade preocupante. Ao mesmo tempo que atraí, expulsa. Esse movimento dialético mostra, dentre outros aspectos, a complexidade da realidade campo; bem como prova que o desenvolvimento capitalista se faz movido pelas suas contradições. Portanto, produção humana, histórica. Esta realidade, assim constituída, própria à lógica imposta pelo capital no campo e se reproduz onde os sistemas, o modo de produção, as relações de produção, são orientadas pela lógica imposta pelo capital.

O campo, este que aí está, poderá constituir-se como um espaço propício da cidadania e de condições de vida, capazes de promover a integração econômica e a emancipação social das populações que aí vivem e trabalham? Num mundo onde o rural/campo e o meio urbano/cidade formam um todo ("unidade contraditória"), qual o sentido do esforço em procurar "fixar" homem ao campo? O êxodo ocorre, nestes casos, como movimento natural e/ou como uma forma de negação daquele espaço para os trabalhadores? Qual o papel da escola neste contexto? O de reproduzir ou possibilitar mudanças? Quais os limites e as possibilidades entre um e outro?

Hoje, as políticas voltadas à juventude do campo não pode estar voltada e/ou limitar-se à agricultura. Isso significa dizer que temos um outro campo sendo gestado. Ou seja, um campo possível de ser visto sob novos paradigmas, qual seja, para além da idéia do campo voltado às atividades agropecuárias. Isso nos leva a concluir que o campo é muito maior do que a agricultura, pecuária, e que ali não vivem só agricultores. 
Portanto, pensar em políticas públicas voltadas para os jovens do campo requer prepará-los, instrumentalizá-los, para essa nova realidade. Estamos falando de educação, necessariamente, sob novos paradigmas, que não aqueles imposto pelo projeto do capital, responsável pela saída/abandono de muitos destes jovens trabalhadores. Esse trabalho educativo poderá começar pela escola. Por isso há que se pensar outra escola. Esse é o desfio maior.

Neste contexto que se (re)desenha, há que se ressaltar a necessidade de se (re)construir no imaginário coletivo, bem como no imaginário da população do campo, uma nova visão do campo. Esse novo olhar sobre o campo e seus sujeitos precisa ser levado também para dentro da escola, inserindo-o nas práticas pedagógicas para que os estudantes (crianças, jovens, adultos) possam incorporálas e vivenciá-las.

Nestas perspectivas, com certeza, dá-se o início - o que já vem ocorrendo à construção de um novo campo, onde a educação seja buscada, fundamentalmente, como um direito, onde a escola seja buscada como um lugar onde se forjam novas idéias e novos ideais. Este é o grande desafio colocado à escola no/do campo hoje.

\section{REFERÊNCIAS BIBLIOGRÁFICAS}

ABRAMOVAY, Ricardo et al. Juventude e Agricultura Familiar: desafios dos novos padrões sucessórios. Brasília: Unesco, 1998.

O futuro das Regiões Rurais. Porto Alegre: Editora da UFRGS, 2003.

CAMARANO, Ana A.; ABRAMOVAY, Ricardo. Éxodo rural, envelhecimento e masculinização no Brasil: panorama dos últimos 50 anos. Disponível em: <http:www.ipea.gov.br/pub/td/td0621.pdfSUMÁRIO>. Acesso em: abr. 2011. 
CARVALHO, Horácio Martins de. O campesinato no século XXI: possibilidades e condicionantes do desenvolvimento do campesinato no Brasil. Petrópolis/RJ: Vozes, 2005.

CASTRO, Elisa G. Os Jovens Estão Indo Embora? Juventude Rural e Reforma Agrária. ITERRA (Instituto Técnico de Educação e Pesquisa da Reforma Agrária. Unidade de Educação Superior - UES. Boletim da Educação - Edição Especial № 11 - Setembro de 2006. Educação Básica de Nível Médio nas Áreas de Reforma Agrária (textos de estudo). São Paulo, 2006.

BRASIL. Constituição da República Federativa do Brasil. Brasília: Senado Federal, 2008.

FREIRE, Paulo. Pedagogia da indignação: cartas pedagógicas e outros escritos. São Paulo: Editora UNESP, 2000.

FERNANDES, Ovil Bueno. Educação e Desintegração Camponesa: o papel da educação formal na desintegração do campesinato. In: VIANA, Nildo; VIEIRA, Renato Gomes. Educação, Cultura e Sociedade: abordagens críticas da escola. Goiânia/GO: Edições Germinal, 2002.

GRZYBOWSKY, Cândido. Esboço de uma alternativa para pensar a educação no meio rural. Contexto \& Educação, São Paulo, ano1, n. 4, p. 47 - 59, out/dez 1986.

HENZ, Celso I. Apresentação. In: BARCELOS, Valdo. Educação de jovens e adultos: currículo e práticas pedagógicas. Petrópolis, RJ: Vozes, 2010. 
LOMBARDI, José C. Educação, Ensino e Formação Profissional em Marx e Engels. In: LOMBARDI, José C; SAVIANI, Dermeval (orgs.). Marxismo e Educação: debates contemporâneos. Campinas/SP: Autores Associados: HISTEDBR, 2005.

MARINHO, E. Reis. Um olhar sobre a educação rural brasileira. Brasília: Universa, 2008.

PERIPOLLI, Odimar João. Amaciando a terra: colonização do Norte de Mato Grosso: o caso Projeto Casulo. (Dissertação de Mestrado) PPGEDU. Porto Alegre, UFRGS, 2002.

- Expansão do capitalismo na Amazônia norte mato-grossense: a mercantilização da terra e da escola: (Tese de Doutorado) PPGEDU. Porto Alegre: UFRGS, 2009.

RIBEIRO, Marlene. Movimento camponês, trabalho e educação: liberdade, autonomia, emancipação: princípios/fins da formação humana. São Paulo: Expressão Popular, 2010.

SAUER, Sérgio. Terra e modernidade: a reinvenção do campo brasileiro. São Paulo: Expressão Popular, 2010.

SCOLESE, Eduardo. A Reforma Agrária. São Paulo: Publifolha, 2005.

\footnotetext{
1 Doutor em Educação pela Universidade Federal do rio Grande do Sul; professor assistente I da Universidade do Estado do Mato Grosso. Email: familiaperipolli@ibest.com.br
} 
${ }^{2}$ Carvalho (2005), ao falar sobre os sem-terra em Mato Grosso, diz que estes se constituem como a cara mais nova do campesinato Mato-grossense.

${ }^{3}$ Ver, sobretudo, a coletânea Por Uma Educação do Campo, UNB/Brasília/DF, diversos autores.

${ }^{4}$ Disponível em: <http:www.ipea.gov.br>.

${ }^{5}$ Vale lembrar que numa perspectiva não reprodutivista, mas transformadora, toda forma de luta no campo se coloca como uma forma de negar o estabelecido. Portanto, deve ser vista como um esforço coletivo para a construção de um projeto de contra-hegemônico.

${ }^{6}$ Em muitos destes assentamentos os trabalhadores vêm assistindo a um processo de "favelização do campo". Para Scolese (2005, p. 147), as maiores queixas e as rotulações de "favelas rurais" aparecem principalmente no momento em que os assentamentos são criados na região amazônica, quando os trabalhadores rurais passam a ser transportados para locais distantes de suas famílias, da infra-estrutura, do mercado consumidor e das condições básicas de saúde e educação. Dar lote não basta [...].

${ }^{7} \mathrm{O}$ conceito de uma e outra está ligado ao acesso ao trabalho, à renda, à moradia, ao transporte, ao lazer, à escola, ao estudo, ou seja, aos direitos sociais $\left(\mathrm{CF} / 1988\right.$, art. $\left.6^{\circ}\right)$.

${ }^{8}$ Abramovay (1998; 2003).

${ }^{9}$ Pesquisas feitas pelo PNRA (2005, apud CASTRO, 2006) mostram que há uma queda significativa na frequiência escolar a partir da $5^{\text {a }}$ série, acentuando-se muito no Ensino Médio. Segundo o estudo, isso se deve, primeiro: às dificuldades quanto ao acesso às escolas; segundo: as escolas de $5^{\mathrm{a}}$ a $8^{\mathrm{a}}$ séries e do Ensino Médio estão nos centros urbanos/cidades. Este quadro é mais significativo/representativo dentro dos assentamentos de Reforma Agrária. Meu/nosso trabalho de campo vem confirmando exatamente este quadro que se reproduz nos quatro cantos do país.

${ }^{10}$ É o caso das universidades públicas de Sinop/MT, Unemat (Universidade do Estado de Mato Grosso) e UFMT (Universidade Federal de Mato Grosso). Mais: o ingresso em uma universidade privada é algo inviável para a renda destas famílias. Já a pública, o que dificulta é o ingresso, a considerar a concorrência. Soma-se a este fato, à falta de condições (custos): manter um filho estudando em uma cidade custa bastante (a considerar a renda/falta de renda destas famílias). Os que trabalham, não conseguem dividir o tempo e os ganhos com os estudos (custos materiais, transporte, etc.).

ENVIADO EM: 15.06.2011

APROVADO EM: 04.07.2011 